\title{
Pengamanan Data Teks Menggunakan Algoritma DES Berbasis Android
}

\author{
Barany Fachri*, Roy Martin Sembiring \\ Fakultas Sains Dan Teknologi, Program Studi Sistem Komputer, Universitas Pembangunan Panca Budi, Medan, Indonesia \\ Email: 1,* barany_fachri@dosen.pancabudi.ac.id, ${ }^{2}$ roymartinsbr180@gmail.com \\ *) Email Penulis Korespondensi: barany_fachri@ dosen.pancabudi.ac.id
}

\begin{abstract}
Abstrak-Smartphone Android tentunya tidak asing lagi di kalangan masyarakat dan tentunya sudah menyebar luas sampai ke dunia. Smartphone Android memiliki banyak aplikasi didalamnya dan juga memiliki fungsi masing-masing dari setiap aplikasi tersebut. Salah satu aplikasi yang umum digunakan adalah pengiriman SMS, yang berfungsi sebagai pengiriman dan penerimaan data dengan cepat. SMS merupakan sebuah pesan teks yang pada saat pengiriman sudah dibatasi dan ditetapkan ukurannya, batasan ukuran tersebut adalah 160 karakter setiap per SMS. Namun setiap pemakaian dan penggunaan SMS ini tentunya dikenakan biaya pengiriman yang sudah ditentukan dari operator. Dengan ini pengamanan menjadi salah satu aspek yang sangat penting untuk menjaga kerahasiaan dan keaslian pesan SMS tersebut agar terhindar dari penyadapan, pencurian maupun orang-orang yang tidak bertanggung jawab. Sehingga sangat diperlukan penerapan pengamanan pada aplikasi SMS ini yang menggunakan kriptografi algoritma DES (Data Encryption Standard) agar pesan yang terkirim ke tujuannya dapat terjaga kerahasiaan dan keasliannya.
\end{abstract}

Kata Kunci : Smartphone Android, Pengamanan SMS, Algoritma DES (Data Encryption Standard)

\begin{abstract}
Android smartphone is certainly no stranger to the public and of course has spread widely to the world. Android smartphone has many applications in it and also has the function of each of these applications. One application that is commonly used is sending SMS, which functions as sending and receiving data quickly. SMS is a text message that at the time of sending has been limited and set its size, the size limit is 160 characters per SMS. But every use and use of SMS is certainly subject to shipping fees that have been determined from the operator. With this, security is one of the most important aspects to maintain the confidentiality and authenticity of the SMS messages so that they avoid being tapped, stolen or irresponsible. So it is very necessary to apply security in this SMS application that uses cryptographic DES (Data Encryption Standard) algorithm so that messages sent to their destinations can be kept confidential and authentic.
\end{abstract}

Keywords: Android Smartphone, SMS Security, DES (Data Encryption Standard) Algorithm

\section{PENDAHULUAN}

Masyarakat tentunya tidak terlepas dari jejaring sosial maupun telepon seluler sebagai sarana untuk alat berkomunikasi. Dalam hal ini tentunya suatu jaringan dalam berkomunikasi sangat rawan terhadap pencurian, penyadapan serta pemalsuan informasi. Pada proses pengiriman data yang melalui suatu jaringan tentunya harus menjamin tingkat keamanan dan keutuhan yang kokoh, sehingga data yang akan dikirim tidak di sadap dan dapat terkirim ke tujuannya. Maka dari itu salah satu cara dalam mengamankan data dari kejadian tersebut, diperlukan penyandian agar data yang dikirim dapat terjaga keamanan dan keasliannya.

Penyandian ini tentunya sangat penting, apalagi dalam strategi bisnis, sebuah perusahaan dan pemerintahan sangat memerlukan teknologi penyandian data atau informasi. Ilmu penyandian adalah ilmu yang sudah banyak dikenal di kalangan umum bahkan dari semenjak zaman Julius Caesar (sebelum masehi). Ilmu penyandian ini tentunya mencakup dari teknik-teknik untuk membongkar sandi dan juga sebagai proses untuk mengubah Plaintext ke Plainbyte, sehingga Plaintext berubah menjadi sebuah kode.

Salah satu media komunikasi yang umum sering digunakan adalah SMS (Short Message Service). SMS adalah sebuah aplikasi yang digunakan untuk mengirim pesan dan menerima pesan masuk yang berupa teks, sehingga banyak diantaranya menggunakan sebagai media komunikasi yang sangat fleksibel dan pada sistem komunikasinya nirkabel. Isi didalam SMS pada dasarnya sangat bermacam-macam mulai dari pesan teks yang biasa hingga sampai pesan teks yang bersifat rahasia, seperti pada pesan perjanjian yang akan ditujukan ke sebuah perusahaan tertentu. Pesan teks yang bersifat rahasia tentunya harus memiliki tingkat keamanan yang tinggi sehingga data yang akan dikirimkan harus di enkripsi terlebih dahulu agar pesan dapat tetap aman dari pihak penyadapan.

Penerapan algoritma DES (Data Encryption Standard) sudah pernah dilakukan sebelumnya untuk pengamanan pesan teks, audio, file dokumen dan lainnya, akan tetapi aplikasi yang dibuat belum terdapat proses dekripsi. Dan pada proses pengiriman yang digunakan pada aplikasi tersebut masih melalui SMS Provider [4]

Berdasarkan penelitian tersebut, menerapkan algoritma DES (Data Encryption Standard) untuk mengamankan data pesan teks dengan proses enkripsi dan dekripsi, kemudian hasil dari pengamanan teks tersebut dapat dikirim melalui SMS Provider dan WhatsApp. DES (Des Encryption Standard) adalah sebuah algoritma yang bersifat cipher blok simetris. Des Encryption Standard dikatakan sebagai cipher blok karena pada pemrosesan data baik dari enkripsi maupun dekripsi yang dikembangkan per blok (menjadi 8 byte). Sehingga banyak diantanya menggunakan DES karena memiliki tingkat keamanan yang kokoh dan sulit untuk dipecahkan. 


\section{METODE PENELITIAN}

\subsection{Keamanan}

Keamanan merupakan hal yang sangat penting untuk menjaga kerahasiaan data dalam sebuah perusahaan, pemerintahan dan perbankan, agar tetap terjaga dengan aman. Data yang bersifat rahasia sangat perlu untuk dibuatkan penyimpanan dan pengirimannya yang khusus, agar data tersebut tidak dapat terbaca dan diubah oleh orang yang tidak bertanggung jawab. Baik data tersebut disimpan dalam sebuah komputer maupun dalam sebuah email. Agar data dapat dikatakan benar-benar aman maka hal yang harus dilakukan adalah tentunya melakukan sistem pengamanan yang sangat baik, yang terbebas dari jangkauan orang-orang yang tidak berhak mengetahuinya, baik dari segi pengamanan fisik maupun secara sistem [1].

\subsection{SMS (Short Message Service)}

SMS (Short Message Service) adalah sebuah layanan untuk mengirim dan menerima pesan teks singkat yang tidak menggunakan kabel, yakni alat yang digunakan untuk mengirimkan SMS ini telepon seluler. Kelebihan SMS ini yang salah satunya adalah biaya pengiriman yang murah. SMS juga menyediakan mekanisme untuk pengiriman pesan teks singkat dan menuju ke media-media wireless menggunakan sebuah Short Messaging Service Center (SMSC), yang bertindak sebagai penyimpanan dan pengiriman kembali pesan-pesan singkat [5].

\subsection{Kriptografi}

Kriptografi adalah teknik tentang kerahasiaan dan keamanan pesan ketika pesan akan dikirim ke tujuannya, sehingga pesan dapat terjaga aman dari penyadapan. Kriptografi umumnya memiliki tiga dasar yang terdiri dari enkripsi, dekripsi dan kunci. Kriptografi fungsi utamanya adalah merahasiakan kunci dan mengubah plainteks ke cipherteks, sehingga plainteks akan berubah menjadi password yang tidak diketahui orang lain, tanpa harus merahasiakan algoritma yang digunakan. Jika setiap kerahasiaan dan keamanan sangat tergantung pada algoritma terutamanya pada sebuah password yang digunakan dapat terbaca oleh orang laian, maka kerahasiaan tersebut tidak aman. Dengan begitu maka algoritma tersebut tidaklah bisa dikatakan dengan aman untuk digunakan sebagai aplikasi berupa pesan teks, gambar, suara, video dan lainnya [2].

\subsection{Algoritma DES}

Algoritma DES (Data Encryption Standard) adalah sebuah algoritma yang berbentuk cipher blok dalam arti yang memiliki kesempurnaan dalam pengamanan SMS yang berupa pesan teks. Algoritma DES sangat terkenal di dunia dan algoritma DES ini dapat dibentukkan ke simetris, meskipun standard namun algoritma DES ini sanngat terjaga kerahasiaannya dan sulit untuk dipecahkan.

DES (Data Encryption Standard) termasuk kedalam sistem kriptografi simetris dan tergolong kedalam jenis cipher blok. DES juga beroperasi dengan ukuran 64 bit. Setiap algoritma DES juga mengenkripsikan dengan jumlah ukuran 64 bit plainteks menjadi 64 bit cipherteks menggunakan 56 bit kunci internal (internal key) atau dengan up-kunci (sub key). Kunci internal yang pada awalnya juga dibangkitkan dari kunci eksternal yang ukuran panjangnya menjadi 64 bit [3].

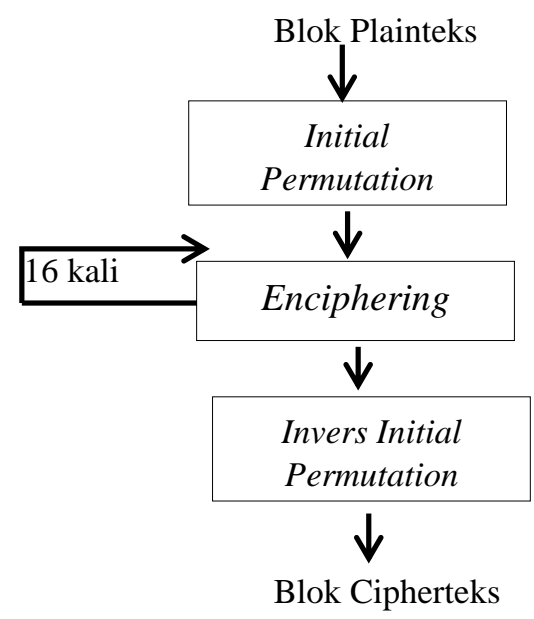

Gambar 1. Skema Global Algoritma DES [3].

\subsection{Android}

Android adalah sistem operasi berfungsi untuk perangkat mobile berbasis linux. Android juga menyediakan berbagai macam platform terbuka bagi para developer dalam membuat aplikasi sederhana. Pada awalnya, Google Inc. membeli Android Inc. yang merupakan pendatang baru dalam piranti smartphone. Untuk 
mengembangkan android, maka saat itu dibentuklah sebuah organisasi yang sekitar 34 perusahaan piranti keras, perangkat lunak maupun telekomunikasi, didalamnya termasuk Google, HTC, Intel, Motorola, Qualcomm, TMobile dan Nvidia.

Android dirilis pertama kalinya pada tanggal 05 November 2007, yang dikenal sebagai android bersama Open Handset Alliance yang mengesahkan android dikembangkan sebagai open source pada perangkat mobile. Kemudian pada sekitar September 2007, Google kembali mengenalkan Nexus One, sebagai salah satu jenis smartphone yang menggunakan android sebagai sistem operasinya. Telepon seluler dibuat dan dikembangkan oleh HTC Corporation. Kemudian pada tanggal 09 Desember 2008, telah diumumkan anggota baru yang bergabung dalam sebuah perusahaan untuk menciptakan versi-versi baru android. Dengan seiring pembentukan OHA (Open Handset Alliance), OHA mengumumkan produk perdana android mereka yang merupakan hasil modifikasi dari kernel Linux 2.6. Sejak android dirilis, maka dari itu juga banyak pembaharuan dan penambahan fitur-fitur yang mendukung berjalannya android tersebut, sehingga android dapat berjalan dengan sempurna dan tidak memiliki kekurangan apapun itu [6].

\section{HASIL DAN PEMBAHASAN}

\subsection{Analisis Masalah}

Perkembangan teknologi dari zaman ke zaman semakin meningkat, khususnya bagi para pengguna smartphone android. Tentunya hal ini menjadi suatu masalah karena kebutuhan manusia akan teknologi pada perangkat informasi maupun komunikasi sudah tidak terkendali dan terpisahkan dalam kehidupan masyarakat. Begitu banyak aplikasi yang ada didalam smartphone android pada saat ini tentunya sangat membantu manusia dalam melakukan aktifitas yang bermanfaat. Aplikasi yang sangat canggih didalam smartphone android sangat banyak dan bermanfaat yang salah satunya adalah pengiriman SMS, dimana manfaat SMS tersebut adalah membantu manusia dalam mengirimkan pesan atau menerima informasi dengan cepat. SMS (Short Message Services) adalah berupa pesan teks yang memiliki ukuran yang sudah ditetapkan dengan maksimal panjang pengiriman SMS sebesar 160 karakter, namun pada saat pengiriman SMS akan dikenakan biaya dari operator yang tergantung seberapa panjang pesan teks tersebut. Kecanggihan teknologi ini yang menyebabkan seringnya pihak yang tidak bertanggung jawab atas panyadapan, pencurian dan pembobolan SMS. Sehingga sangat penting untuk sebuah pengamanan SMS agar pesan teks yang dikirim maupun yang diterima masih terjamin kerahasiaan dan keaslian pesan ttersebut. Setiap pengiriman SMS sangat dibutuhkan alat pendukung yang salah satunya adalah smartphone android.

Aplikasi SMS ini merupakan sangat bermanfaat untuk banyak orang terutamnya pada perusahaan dan lainnya. Tampilan desain aplikasi keamanan SMS yang natinya akan dibuat, sebagai berikut:

a. Splash, adalah berfungsi sebagai tampilan awal pembuka untuk menuju ke menu utama aplikasi.

b. Menu utama, adalah tampilan awal dalam menentukan pilihan yang akan digunakan.

c. Tulis pesan, berfungsi untuk menuliskan sebuah pesan yang akan dikirimkan ke tujuannya.

d. Baca pesan, berfungsi untuk membaca pesan sebelum pesan tersebut akan dikirimkan ke tujuannya.

e. Kirim pesan, adalah untuk mengirimkan pesan ke tujuannya.

\subsection{Perangkat Yang Digunakan Untuk Aplikasi Pengamanan SMS (Short Message Service)}

Dalam penerapan aplikasi keamanan SMS ini menggunakan perangkat pendukung agar aplikasi yang dibuat dapat berjalan dengan baik sesuai dengan perencanaan. Adapun perangkat yang digunakan terbagi menjadi dua bagian, sebagai berikut:

\subsection{Teknik Pemecahan Masalah Keamanan SMS (Short Message Service)}

Pada aplikasi keamanan SMS (Short Message Service) ini mempunyai beberapa poin teknik dalam pemecahannya, sebagai berikut:

a. Untuk langkah awal dalam perancangan dan pembuatan aplikasi keamanan SMS ini akan menggunakan alat pendukung adalah smartphone android.

b. Perancangan aplikasi ini membutuhkan perangkat keras maupun perangkat lunak dalam membangun aplikasi keamanan SMS ini hingga berjalan sesuai dengan rancangan.

c. Sehingga pada perancangan sistem ini yang nantinya akan diterapkan (implementasikan) pada aplikasi yang akan dibangun.

d. Kemudian pada proses pengujian ini akan dilakukan secara keseluruhan termasuk saat input maupun output data, dimana bertujuan untuk mengetahui apakah perancangan sistem sudah sesuai dengan rencana yang sebelumnya dibuat.

\subsection{Analisis Proses Penyelesaian Keamanan SMS (Short Message Service)}

Banyak diantaranya algoritma yang dapat menjaga keamanan SMS, sehingga tetap data yang diperoleh masih sangat bersifat rahasi. Dari penelitian yang diperoleh bahwa dalam aplikasi keamanan SMS ini digunakan algoritma DES (Data Encryption Standard) karena algoritma ini merupakan salah satu algoritma yang sulit 
untuk dipecahkan dan umumnya beroperasi dengan ukuran blok 64 bit. Algoritma DES (Data Encryption Standard) juga termasuk dalam kriptografi simetris yang tergolong pada jenis cipher blok. Pada saat aplikasi SMS dirancang, terdapat beberapa kriteria keamanan algoritma DES, sebagai berikut:

a. Cepat, DES memiliki kunci eksternal dengan ukuran panjangnya 64 atau 8 karakter.

b. DES (Data Encryption Standard) juga memiliki operasi-operasi sederhana untuk dapat dijalankan seperti: penambahan dan bilangan XOR.

c. Memiliki tingkat keamanan yang sulit untuk dipecahkan, sehingga data yang dienkripsi sangat bersifat rahasia, aman, serta terhindar dari pihak yang tidak bertanggung jawab.

\subsection{Enkripsi Data Algoritma DES (Data Encryption Standard)}

Enkripsi data menggunakan algoritma DES (Data Encryption Standard) dapat dilakukan dengan perhitungan sebagai berikut:

Contoh :

Plaintext : komputer

Key DES : : martinsb

Dari soal diatas terdapat plaintext dan key yang dapat dipecahkan, sebelum kita memulai untuk melakukan enkripsi data, maka yang harus dilakukan terlebih dahulu untuk mengubah plaintext dan key ke bentuk biner.

Tabel 1. Pengoprasian PC-1

$\left.\begin{array}{ll}\hline \text { Plaintext } & \text { Key } \\ \hline \mathrm{k}(6 \mathrm{~B})=01101011 & \mathrm{~m}(6 \mathrm{D})=01101101 \\ \mathrm{o}(6 \mathrm{~F})=01101111 & \mathrm{a}(61)=01100001 \\ \mathrm{~m}(6 \mathrm{D})=01101101 & \mathrm{r}(72)=01110010 \\ \mathrm{p}(70)=01110000 & \mathrm{t}(74)=01110100 \\ \mathrm{u}(75)=01110101 & \mathrm{i}(69)=01101001 \\ \mathrm{t}(74)=01110100 & \mathrm{n}(6 \mathrm{E})=01101110 \\ \mathrm{e}(65)=01100101 & \mathrm{~s}(73)=01110011 \\ \mathrm{r}(72)=01110010 & \mathrm{~b}(62)=01100010\end{array}\right] \quad \mathbf{C}_{\mathbf{0}}$

$\mathrm{P}=0110101101101111011011010111000001110101011101000110010101110010$

\subsection{Perancangan Sistem}

Pada proses perancangan keamanan SMS (Short Message Service) ini akan menjelaskan tentang gambaran rancangan aplikasi yang nantinya akan dikerjakan pada android studio, serta untuk menjalankannya akan dihubungkan ke perangkat smartphone android. Rancangan aplikasi tersebut akan dilakukan dari tahapan awal hingga sampai akhir, sebagai berikut:

\section{Use Case Diagram}

Use Case Diagram disini menggambarkan tentang skenario aplikasi agar pengguna dapat memahami rancangan aplikasi keamanan SMS yang akan dibuat. Gambar dapat dilihat dibawah ini:

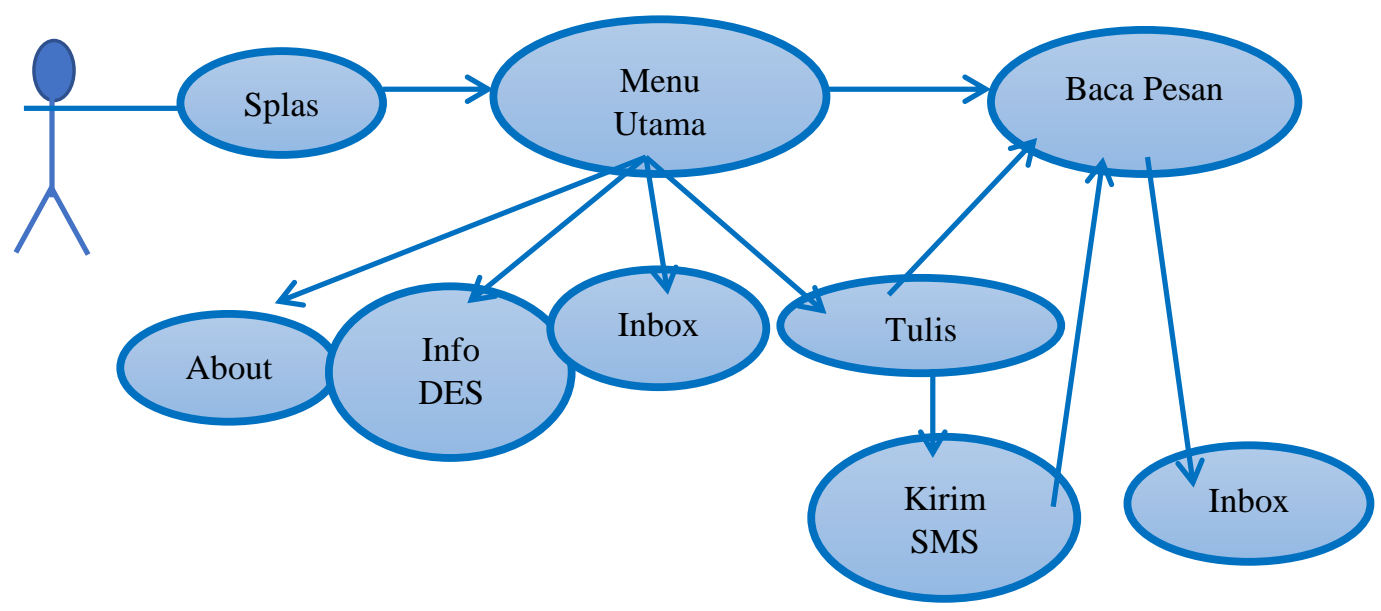

Gambar 2. Tampilan Use Case Diagram 
JURNAL MEDIA INFORMATIKA BUDIDARMA

Volume 4, Nomor 1, Januari 2020, Page 110-116

ISSN 2614-5278 (media cetak), ISSN 2548-8368 (media online)

Available Online at https://ejurnal.stmik-budidarma.ac.id/index.php/mib DOI 10.30865/mib.v4i1.1700

\subsection{Implementasi}

Pada pembahasan ini akan menjelaskan tentang tampilan aplikasi yang telah dibuat, dimana untuk memperjelas setiap gambar yang di masukkan. Sehingga hasil implementasi dari aplikasi enkripsi SMS ini akan sesuai dari perancangan dan program yang telah dibuat. Untuk melihat tampilan dari tahap ke tahap yang ditampilkan pada aplikasi enkripsi SMS ini dapat dilihat dengan jelas dibawah ini.

\section{Tampilan Pembuka (Splash)}

Pada tampilan ini berfungsi sebagai menu pembuka (loading), dimana sebagai awal sebelum menuju ke menu utama aplikasi. Tampilan pembuka (splash) dapat dilihat pada gambar 3

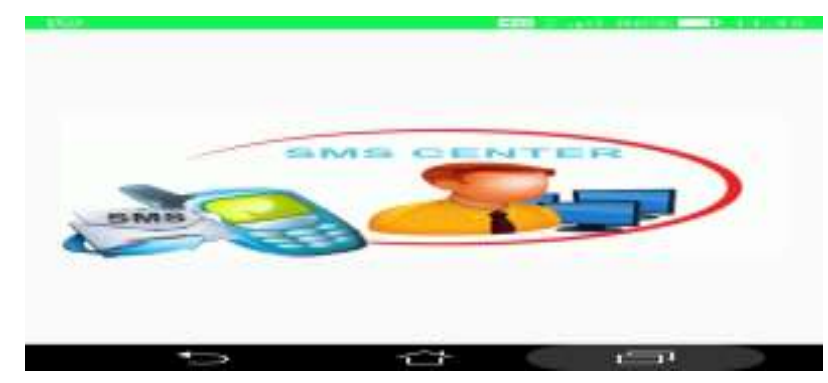

Gambar 3. Tampilan Pembuka (Splash)

\section{Tampilan Menu Utama}

Pada tampilan ini akan menampilkan menu pilihan yang nantinya akan di uji coba setiap pengguna. Sehingga pengguna dapat mengakses dari setiap menu-menu yang ditampilkan. Tampilan menu utama dapat dilihat pada gambar 4.

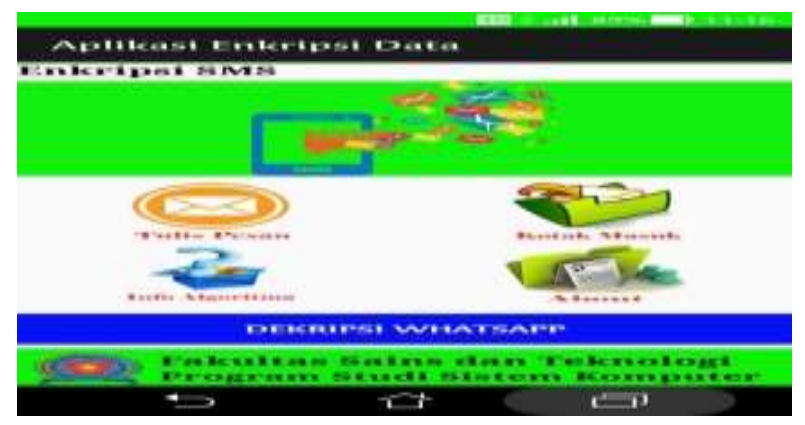

Gambar 4. Tampilan Menu Utama Aplikasi

\section{Tampilan Tulis Pesan}

Tampilan ini berfungsi untuk mengetik sebuah pesan baru, di mana pesan tersebut akan dikirimkan ke tujuannya. Tampilan menu tulis pesan dapat dilihat pada gambar 5.

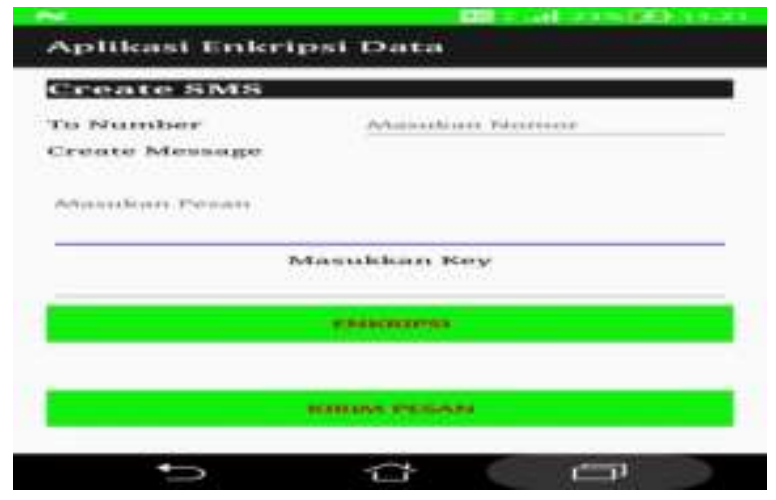

Gambar 5. Tampilan Tulis Pesan

\section{Tampilan Kotak Masuk}

Menu ini akan menampilkan hasil dari setiap pesan masuk yang terdapat pada Smartphone Android. Tampilan menu kotak masuk dapat dilihat pada gambar 6 . 


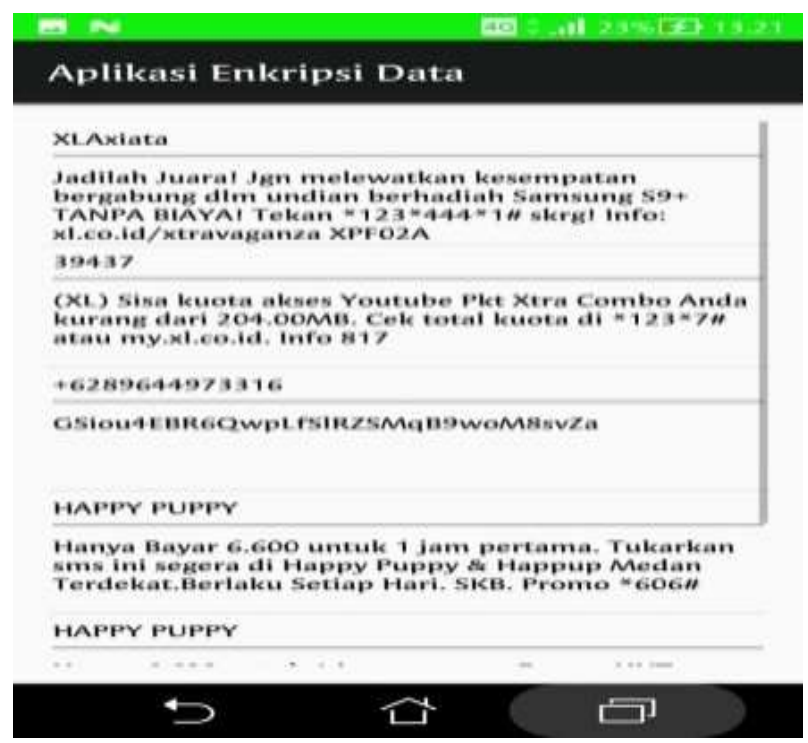

Gambar 6. Tampilan Menu Kotak Masuk

\section{Tampilan Hasil Dekripsi}

Tampilan ini adalah untuk menerjemahkan pesan yang sebelumnya pesan tersebut dikirim dalam bentuk enkripsi atau kode. Tampilan hasil dekripsi dapat dilihat pada gambar 7.

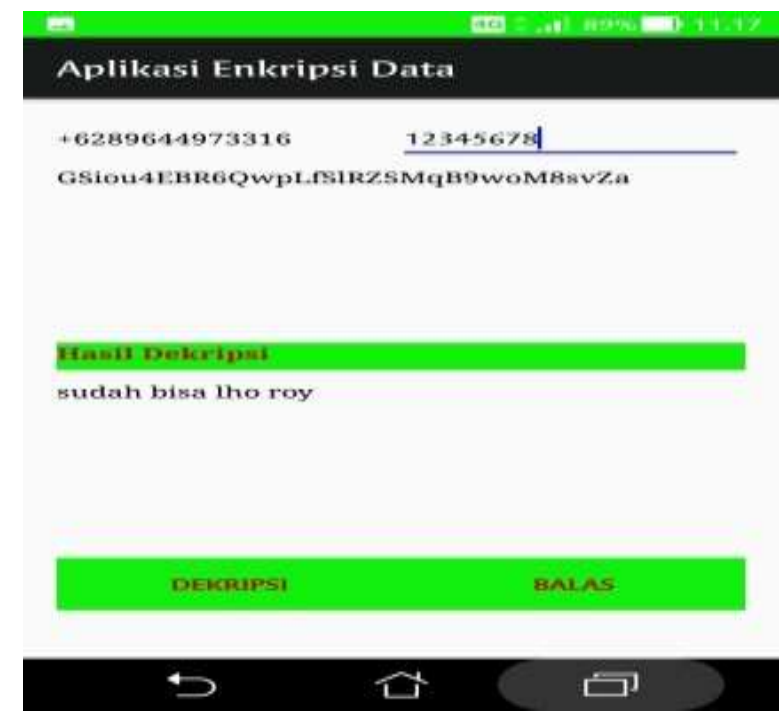

\section{KESIMPULAN}

Dari pembahasan di atas tentang "Implementasi Algoritma DES (Data Encryption Standard) Untuk Mengamankan Data Berbasis Android", penulis dapat menarik beberapa kesimpulan yang mana nantinya dapat berguna bagi para pembaca dan juga mayarakat umum lainnya. Beberapa kesimpulan dapat dilihat sebagai berikut:

a. Perancangan aplikasi ini dibangun dari awal dengan tujuan untuk mengamankan data (pesan teks), sehingga data yang terkirim tidak dapat di baca dan dimengerti oleh orang yang tidak bertanggung jawab.

b. Pada aplikasi SMS ini mampu mengembalikan pesan yang terenkripsi kembali ke hasil pesan aslinya yaitu dekripsi.

c. Aplikasi SMS ini terdapat dua pilihan proses pengiriman yaitu, proses pengiriman melalui SMS Provider dan Whatshapp.

d. Algoritma DES (Data Encryption Standard) yang digunakan pada aplikasi ini hasil output sama.

e. Pada perancangan aplikasi SMS ini menggunakan bahasa pemrograman java sebagai compiler java, di mana sebagai bahasa pemrograman utama android studio.

f. Dalam pembuatan aplikasi SMS ini menggunakan software bantuan dalam menyempurnakan aplikasi tersebut yaitu android studio sebagai editor program. 
JURNAL MEDIA INFORMATIKA BUDIDARMA

Volume 4, Nomor 1, Januari 2020, Page 110-116

ISSN 2614-5278 (media cetak), ISSN 2548-8368 (media online)

Available Online at https://ejurnal.stmik-budidarma.ac.id/index.php/mib

DOI $10.30865 /$ mib.v4i1.1700

\section{REFERENCES}

[1] B. Fachri, A. P. Windarto, and I. Parinduri, "Penerapan Backpropagation dan Analisis Sensitivitas pada Prediksi Indikator Terpenting Perusahaan Listrik," J. Edukasi dan Penelit. Inform., vol. 5, no. 2, p. 202, 2019, doi: 10.26418/jp.v5i2.31650.

[2] M. Mesran, “Aplikasi Sistem Informasi Akademik Berbasis Online,” Pelita Inform., vol. I, pp. 5-10, 2012.

[3] A. P. Windarto et al., "Analysis of the K-Means Algorithm on Clean Water Customers Based on the Province," $J$. Phys. Conf. Ser., vol. 1255, no. 1, 2019, doi: 10.1088/1742-6596/1255/1/012001.

[4] N. R. Yanti, A. Alimah, and D. A. Ritonga, "Implementasi Algoritma Data Encryption Standard Pada Penyandian Record Database," J-SAKTI (Jurnal Sains Komput. dan Inform., vol. 2, no. 1, p. 23, 2018, doi: 10.30645/jsakti.v2i1.53.

[5] M. Afrina and A. Ibrahim, "Pengembangan Sistem Informasi SMS Gateway Dalam Meningkatkan Layanan Komunikasi Sekitar Akademika Fakultas Ilmu Komputer Unsri," J. Sist. Inf., vol. 7, no. 2, pp. 852-864, 2015.

[6] E. Maiyana, "Pemanfaatan Android Dalam Perancangan Aplikasi Kumpulan Doa," J. Sains dan Inform., vol. 4, no. 1, pp. 54-65, 2018, doi: 10.22216/jsi.v4i1.3409. 